\title{
Clinical Endocrinology: A Review of Adrenal Gland Hormonal and Endocrine
} Metabolic Disorders

\section{${ }^{1 *}$ Navya K}

Department of Pharmacy Kakatiya University, Warangal, India

Corresponding Author : Navya K, Department of Pharmacy Kakatiya University, Warangal, India. E-mail: mailto:navyakasturi9@gmail.com Received date: March 05,2017;Accepted date : April 23,2017; Published date: May $20,2017$.

Citation for this Article: Navya K, Clinical Endocrinology: A Review of Adrenal Gland Hormonal and Endocrine Metabolic Disorders, Journal of Endocrinology and Disorders, Doi: 10.31579/2640-1045/003

Copyright : @ 2017. Navya K This is an open-access article distributed under the terms of the Creative Commons Attribution License, which permits unrestricted use, distribution, and reproduction in any medium, provided the original author and source are credited.

\begin{abstract}
\section{Adrenal Gland}

The adrenal glands are controlled in part by the brain. The hypothalamus, a small area of the brain involved in hormonal regulation, produces corticotropin-releasing hormone $(\mathrm{CRH})$ and vasopressin (also known as antidiuretic hormone). Vasopressin and CRH trigger the pituitary gland to secrete corticotropin (also known as adrenocorticotropic hormone or ACTH), which stimulates the adrenal glands to produce corticosteroids. The renin-angiotensin-aldosterone system, regulated mostly by the kidneys, causes the adrenal glands to produce more or less aldosterone.

The body controls the levels of corticosteroids according to need. The levels tend to be much higher in the early morning than later in the day. When the body is stressed, due to illness or otherwise, the levels of corticosteroids increase dramatically.
\end{abstract}

\section{Introduction}

\section{Adrenal Gland Hormonal and Metabolic Disorders}

Disorders of the adrenal gland can involve the secretion of too little or too much hormone.

When too little hormone is secreted, it may be because of a problem with the adrenal gland itself (a primary disorder, such as Addison disease). Or it may be due to a problem elsewhere in the body, such as the pituitary gland or the hypothalamus. For example, a problem with the pituitary gland could mean that the adrenal glands are not being stimulated to secrete hormones.

When too much hormone is secreted (oversecretion), the disorder that results depends on the hormone:

- Oversecretion of glucocorticoids: Cushing syndrome

- Oversecretion of aldosterone: Hyperaldosteronism

- Oversecretion of epinephrine and norepinephrine: Pheochromocytoma

- Oversecretion of androgens: Virilization

Hypercortisolism involves the overproduction of the adrenal hormone cortisol. This can be due to over-stimulation from the pituitary gland from the hormone ACTH (see Cushing's disease in the pituitary section), or from a problem within the adrenal gland itself, either from a single cortisol-secreting adrenal mass or from nodular adrenal disease.

Excess cortisol in the blood can cause a variety of symptoms, including high blood pressure, weight gain, thinning of the skin, easy bruising, poor wound healing and many others (sometimes referred to as Cushing's syndrome). The diagnosis of hypercortisolism is made by blood and/or urine testing. Treatment depends upon cause of the excess cortisol secretion. In the case of a solitary adrenal mass, surgical removal can be curative. However, for other types of hypercortisolism, surgery may not be possible, so medication is used.
Hyperaldosteronism involves the overproduction of the adrenal hormone aldosterone. This can result in low potassium in the blood and high blood pressure that does not respond to usual treatment. The underlying causes of this include a single adrenal mass, or nodular adrenal disease.

The diagnosis is made by blood tests and may require further specialized testing, including adrenal vein sampling which is done by inserting a catheter into the adrenal veins to measure the aldosterone levels. Treatment depends upon the cause. If a single mass is identified as the source of the excess hormone production, then it can usually be surgically removed. However, if the source is nodular disease that involves both adrenal glands (right and left), then surgery may not be possible and medication is used. The investigation and treatment of hyperaldosteronism should be guided by a specialist familiar with this condition.

Adrenal insufficiency involves reduced hormone secretion from the adrenal gland, resulting in a deficiency of all adrenal hormones, including cortisol and aldosterone. Symptoms of adrenal insufficiency include weakness, weight loss, dizziness, and sometimes abdominal pain, nausea and vomiting.

The causes of adrenal insufficiency include autoimmune destruction of the adrenal gland (Addison's disease), bleeding into the adrenal glands, or infections, such as tuberculosis. If the adrenal glands are severely damaged, they do not usually recover and hormone replacement is required.

Hormone replacement for adrenal insufficiency includes cortisol-like medications (e.g. hydrocortisone or prednisone) and aldosterone-like medications (fludrocortisone). The proper doses of each of these medications varies between individuals and should be determined in conjunction with a specialist, who is familiar with the treatment of this condition.

The adrenal gland, like other glands in the body, can develop masses (lumps) within the gland, which are usually benign (non-cancerous) and do not cause any problem. 
However, some adrenal masses can produce excess adrenal hormones, including cortisol, aldosterone, or epinephrine. Also, rarely adrenal masses can be cancerous.

\section{Adrenal Mass}

An adrenal mass may be identified incidentally by a ultrasound, CT scan or MRI. In such cases, testing should be done to make sure that the mass is not producing too much hormone and that it is not cancerous. If the mass is cancerous or produces too much hormone, then surgical removal is usually necessary. If the mass is noncancerous and does not produce excess hormone, then simple clinical monitoring is often the best course of action.

\section{Cushing syndrome}

Cushing syndrome (also sometimes called Cushing's syndrome) consists of the physical and mental changes that result from having too much cortisol in the blood for a long period of time. Cortisol is a steroid hormone produced by the adrenal glands, located above the kidneys. In normal amounts, cortisol helps the body.

\section{Adrenal Incidentaloma}

An adrenal incidentaloma is an unsuspected tumor in one or both of your adrenal glands. This type of tumor is usually found by chance during an imaging test, such as an ultrasound or CT scan, for another condition.

\section{Congenital adrenal hyperplasia}

Congenital adrenal hyperplasia, also called $\mathrm{CAH}$, is a genetic disorder in which the two adrenal glands do not function properly because of mutations in the gene for steroid 21-hydroxylase. Affected children inherit an abnormal copy of the gene from each of their parents. One abnormal copy of the gene ("a carrier") does not cause CAH. The adrenal glands, located on top of each kidney, make important hormones, such as cortisol, that are essential for body functions.

The genetic defect in $\mathrm{CAH}$ leads to abnormal Steroid 21-hydroxylase is an enzyme, (a protein that causes a chemical change in the body) activity in the adrenal glands, that are is needed for proper function. Without the enzyme, the adrenal glands may produce too little (or nothing) of the hormones cortisol and/or aldosterone and too much androgen. CAH can be severe (classic) or mild (non-classic)

\section{Thyroid disorders}

Hypothyrodism and hyperthyroidism can both be due to a number of causes, one of which is metabolic dysfunction. Hypothyroidism is caused by undersecretion, of thyroid hormones. In one form of childhood hypothyroidism, children born with abnormally small thyroids produce insufficient levels of the thyroid hormones T3 and T4, which are important for metabolically directed bone development. If detected in the first 6 months of life, this disorder can be treated with synthetic thyroid hormones such that its effects can be avoided. The most severe early onset hypothyroidisms are characterized by Cretinism, a type of dwarfism, and mental retardation. Adult hypothyroidism is called myxedema. Myxedema symptoms include slowed speech, yellowed skin, and generally slowed body functions. Myxedema can also be treated with synthetic T4, but if left untreated, can lead to coma.

Hyperthyroidism, caused by oversecretion of thyroid hormones, is marked by an overall rapid metabolism including a rapid pulse, high body temperature, and agitation. The most common form of hyperthyroidism in children and adults is Grave's disease, which is clinically distinguished by the appearance of an enlarged thyroid, or goiter, that grows at the front of the neck. Grave's disease is thought to be a malfunction of the immunological functions involving the thyroid.

\section{Treatments for adrenal gland disorders}

Health care providers use a variety of surgical and medical treatments for adrenal gland disorders. These include
- Surgery to remove tumors in the adrenal gland or, when appropriate, surgery to remove the one or both of the adrenal glands

- Minimally invasive surgery performed through the nostrils to remove tumors in the pituitary gland

- Medication to stop the excess production of hormones

- Hormone replacement

\section{Adrenal Crisis Treatment \& Management}

- Administration of glucocorticoids in supraphysiologic or stress doses is the only definitive therapy.

Dexamethasone does not interfere with serum cortisol assay and, thus, may be the initial drug of choice. However, because dexamethasone has little mineralocorticoid activity, fluid and electrolyte replacement are essential.A short ACTH stimulation test may be performed during resuscitation. Once complete, hydrocortisone $100 \mathrm{mg}$ IV every 6 hours is the preferred treatment to provide mineralocorticoid support.Delaying glucocorticoid replacement therapy while awaiting the results of the ACTH stimulation test is inappropriate and dangerous.

\section{Conclusion}

It is important that there be a more complete definition of the prevalence and incidence of endocrine and metabolic diseases. To accomplish this goal, future epidemiological studies should incorporate hormonal measures that can be accurately determined in the population setting. Measures such as intact PTH, IGF-I, and pituitary hormones (i.e. TSH, $\mathrm{FSH}$, and LH) should be incorporated. Sex hormones (i.e. testosterone, estradiol), which have been measured in prior studies, can now be more accurately determined using liquid chromatography tandem-mass spectrometry, a newer laboratory technique.

\section{References}

1. Cowie CC, Rust KF, Byrd-Holt DD, Eberhardt MS, Flegal KM, Engelgau MM, Saydah SH, Williams DE, Geiss LS, Gregg EW 2006. Prevalence of diabetes and impaired fasting glucose in adults in the U.S. population: National Health and Nutrition Examination Survey 1999-2002. Diabetes Care 29:1263-1268.

2. Mokdad AH, Bowman BA, Engelgau MM, Vinicor F 2001. Diabetes trends among American Indians and Alaska natives: 19901998. Diabetes Care 24:1508-1509.

3. Ford ES, Li C, Zhao G, Pearson WS, Mokdad AH 2008. Prevalence of the metabolic syndrome among U.S. adolescents using the definition from the International Diabetes Federation. Diabetes Care 31:587-589

4. 2008 State-specific prevalence of obesity among adults-United States, 2007. MMWR Morb Mortal Wkly Rep 57:765-768

5. Jemal A, Siegel R, Ward E, Hao Y, Xu J, Murray T, Thun MJ 2008. Cancer statistics, 2008. CA Cancer J Clin 58:71-96

6. Rizza RA, Vigersky RA, Rodbard HW, Ladenson PW, Young Jr WF, Surks MI, Kahn R, Hogan PF 2003. A model to determine workforce needs for endocrinologists in the United States until 2020. J Clin Endocrinol Metab 88:1979-1987

7. Gardner DG, Shoback D 2007. Greenspan's basic and clinical endocrinology. 8th ed. New York: McGraw-Hill

8. Larsen PR, Kronenberg HM, Melmed S, Polonsky KS 2003. Williams textbook of endocrinology. 10th ed. Philadelphia: Saunders, An Imprint of Elsevier

9. DeGroot LJ, Jameson, JL 2005. Endocrinology. 5th ed Philadelphia: Saunders, An Imprint of Elsevier

10. Nussey SS, Whitehead SA 2001. Endocrinology: an integrated approach. London: Taylor and Francis Group. Available online at Last accessed 12/17/2007

11. website, published by MDTEXT.COM, INC, S. Dartmouth, MA. Last accessed 12/17/2007

12. National Diabetes Data Group 1995. Diabetes in America. 2nd ed. Bethesda, MD: National Institutes of Health Publications.

13. Lindsay R, Feldkamp M, Harris D, Robertson J, Rallison M 1994. Utah Growth Study: growth standards and the prevalence of growth hormone deficiency. J Pediatr 125:29-35. 
13. Yue NC, Longstreth Jr WT, Elster AD, Jungreis CA, O'Leary DH, Poirier VC 1997. Clinically serious abnormalities found incidentally at MR imaging of the brain: data from the Cardiovascular Health Study. Radiology 202:41-46 .

14. Surawicz TS, McCarthy BJ, Kupelian V, Jukich PJ, Bruner JM, Davis FG 1999. Descriptive epidemiology of primary brain and CNS tumors: results from the Central Brain Tumor Registry of the United States, 1990-1994. Neuro Oncol 1:14-25.
15. Hollowell JG, Staehling NW, Flanders WD, Hannon WH, Gunter EW, Spencer CA, Braverman LE 2002. Serum TSH, T(4), and thyroid antibodies in the United States population (1988 to 1994): National Health and Nutrition Examination Survey (NHANES III). J Clin Endocrinol Metab 87:489-499

16. Rallison ML, Dobyns BM, Meikle AW, Bishop M, Lyon JL, Stevens W 1991. Natural history of thyroid abnormalities: prevalence, incidence, and regression of thyroid diseases in adolescents and young adults. Am J Med 91:363-370 . 